\title{
Progress in the Synthesis of Heterocyclic Compounds Catalyzed by Lipases
}

\author{
Xiao-Long Ma ${ }^{1}$ Yu-Han Wang ${ }^{1}$ Jin-Hua Shen ${ }^{1} \quad \mathrm{Yi} \mathrm{Hu}^{1}{ }^{1 *}$ \\ ${ }^{1}$ State Key Laboratory of Materials-Oriented Chemical Engineering,
School of Pharmaceutical Sciences, Nanjing Tech University,
Nanjing, People's Republic of China \\ Pharmaceut Fronts 2021;3:e87-e97. \\ Address for correspondence Yi Hu, phD, State Key Laboratory of \\ Materials-Oriented Chemical Engineering, School of Pharmaceutical \\ Sciences, Nanjing Tech University, 30 South Puzhu Road, Pukou \\ District, Nanjing 211800, People's Republic of China \\ (e-mail: huyi@njtech.edu.cn).
}

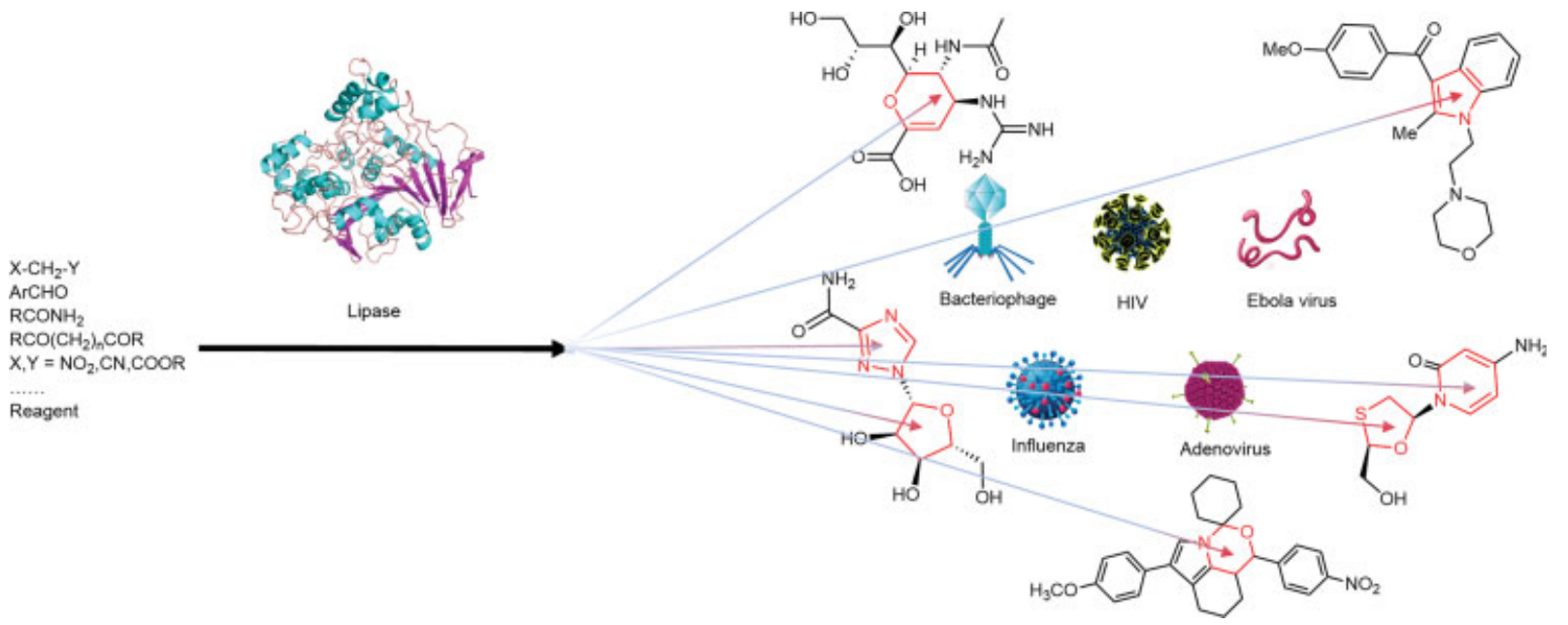

\section{Abstract \\ Keywords \\ - lipases \\ - synthesis \\ - heterocyclic compounds}

Heterocyclic compounds are representative of a larger class of organic compounds, and worthy of attention for many reasons, chief of which is the participation of heterocyclic scaffolds in the skeleton structure of many drugs. Lipases are enzymes with catalytic versatility, and play a key role in catalyzing the reaction of carbon-carbon bond formation, allowing the production of different compounds. This article reviewed the lipase-catalyzed aldol reaction, Knoevenagel reaction, Michael reaction, Mannich reaction, etc., in the synthesis of several classes of heterocyclic compounds with important physiological and pharmacological activities, and also prospected the research focus in lipase-catalyzed chemistry transformations in the future.

\section{Introduction}

Heterocyclic compounds have important applications in the field of medicine, chemistry, materials science, etc. ${ }^{1-5}$ For example, five- or six-membered heterocyclic compounds containing nitrogen or oxygen are the skeleton structures of many important clinical drugs (-Fig. 1). As we know, synthesis protocols for heterocyclic compounds are traditionally focused on ionic liquid-, nanoparticle-, or solid acid-catalyzed, and ultrasonic radiation-promoted reactions, which are commonly accompanied by unfavorable reaction conditions, including high temperature, employing catalysts being identified as nonrecyclable, expensive or commercially unavailable materials, and inevitably using toxic or volatile organic solvents. received

June 16, 2021

accepted

August 13, 2021
DOI https://doi.org/

$10.1055 / \mathrm{s}-0041-1736233$

ISSN 2628-5088. (c) 2021. The Author(s).

This is an open access article published by Thieme under the terms of the Creative Commons Attribution License, permitting unrestricted use, distribution, and reproduction so long as the original work is properly cited. (https://creativecommons.org/licenses/by/4.0/)

Georg Thieme Verlag KG, Rüdigerstraße 14, 70469 Stuttgart, Germany 


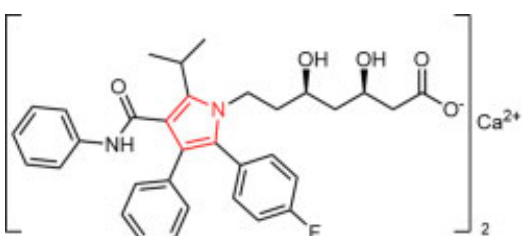

Atorvastatin

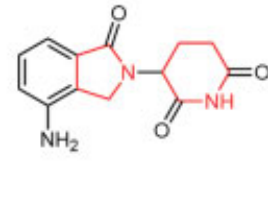

Lenalidomide

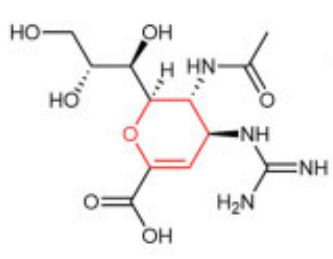

Zanamivir

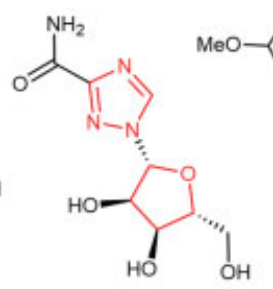

Ribavirin

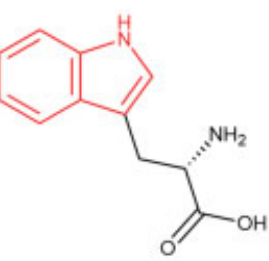

Tryptophan

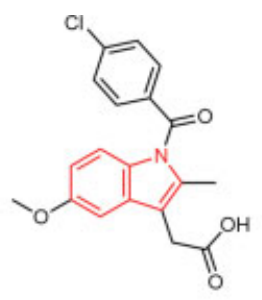

Indomethacin
Fig. 1 Several skeleton structures of heterocyclic compounds that are widely used in clinical setting.

With the character of high efficiency, specificity, and mildness, biocatalysis has been a hotspot in the field of green synthetic chemistry. Biocatalysts lipases are the most commonly used enzymes in synthetic organic chemistry, and favor the reaction with mild reaction conditions, as well as require low amounts of coenzymes. ${ }^{6,7}$ This article reviews the latest research in lipase-catalyzed synthesis of heterocyclic compounds, including five- and six-membered nitrogencontaining and oxygen-containing heterocyclic compounds or others synthesized in recent years, which may provide a valuable reference for green synthesis of heterocyclic compounds.

\section{Lipase-Catalyzed Synthesis of Heterocyclic Compounds}

\section{Synthesis of Five-Membered Heterocyclic Compounds}

\section{Synthesis of Five-Membered Heterocyclic Compounds} Containing Nitrogen

Pyrrole and its derivatives occur widely in nature and possess bioactivity in medicine field, such as captopril (an angiotensin-converting enzyme inhibitor for hypertension therapy), ${ }^{8}$ atorvastatin (a hydroxymethylglutaryl coenzyme A reductase inhibitor for blood lipid regulation), ${ }^{9}$ and the anticancer drug pyrotinib (an irreversible pan-ErbB inhibitor). ${ }^{10}$ In addition to the medicine field, the application of pyrrole compounds in materials science is also emerging, expanding and deepening gradually. ${ }^{11}$

As we all know, the Paal-Knorr reaction represents an effective and simple method to synthesize pyrrole. In 2013, Zheng et al used enzymes to catalyze the Paal-Knorr reaction for the preparation of pyrrole derivatives (-Scheme 1). ${ }^{12}$ They screened samples of commercially available enzymes for their ability to catalyze the model reaction of the PaalKnorr reaction using 2,5-hexanedione and aniline as reaction materials. They found that lipase led to moderate yields

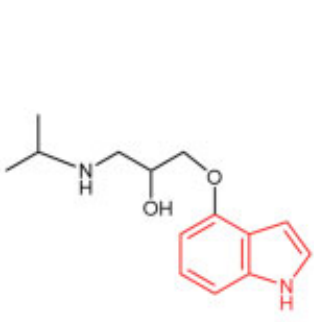

Pindolel

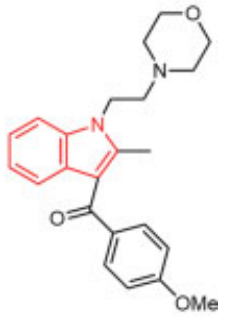

Pravadoline
Fig. 2 Structures of indole natural products and pharmaceuticals.

(47 and 53\% yields for Amano lipase M from Mucor javanicus and Lipase AT30, respectively) when compared with those of amylase and protease (60-99\% yields).

Indole (benzopyrrole) is one of the important pyrrole derivatives with various bioactive activities, including antibacterial, anti-inflammatory, antitumor, antioxidation, and hypoglycemic activity, and has been extensively studied in the fields of medicine, materials science, food, fragrances, dyes, etc. $^{13,14}$ - Fig. 2 lists some indole derivatives that are clinically used as pharmaceuticals. In 2021, Li et al first reported Candida rugosa lipase (CRL)-catalyzed reaction of 1,3-diketones with fumaronitrile to synthesize polycyanosubstituted indole with moderate to excellent yields (- Scheme 2A). ${ }^{15}$ This report also suggested that steric hindrance of $R_{1}$ and $R_{2}$ decreased the total yield of the target product. Encouragingly, when the substrate is an asymmetric 1,3-diketone, a higher regioselectivity and total yield of the reaction were achieved when compared with a chemical catalysis method. Unfortunately, in this reaction, $R_{1}$ and $R_{2}$ are limited to electron-donating alkyl groups, and the 1,3dione compound should not be a $\beta$-ketoester (for example, diethyl malonate and methyl acetoacetate). This result suggested that choosing CRL as a catalysis favored a higher regioselectivity of the reaction, which made this enzymatic method more attractive than the chemical method. ${ }^{16} \mathrm{~A}$ plausible reaction mechanism for this process is depicted in -Scheme 2B: briefly, an enol anion is generated from acetyl acetone $\mathbf{1}$ under the action of the Asp-His dyad and stabilized by the oxyanion; the interaction between the enol

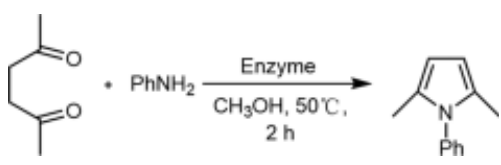

Scheme 1 Enzyme-catalyzed Paal-Knorr reaction for the synthesis of pyrrole compounds. 
A<smiles>[R]C(=O)CC([R])=O</smiles>

$\mathrm{R}_{1}=\mathrm{R}_{2}=\mathrm{Me}, \mathrm{Et}, i-\mathrm{Pr}, t-\mathrm{Bu}, i-\mathrm{Bu} ; 57 \%-88 \%$ yield

$\mathrm{R}_{1} \neq \mathrm{R}_{2}, \mathrm{R}_{1}$, or $\mathrm{R}_{2}=\mathrm{Me}$, Et, $i-\mathrm{Pr}, t-\mathrm{Bu}, i-\mathrm{Bu}, \mathrm{CH}\left(\mathrm{CH}_{3}\right)_{2},\left(\mathrm{CH}_{2}\right)_{4} \mathrm{CH}_{3} ; 63 \%-85 \%$ yield

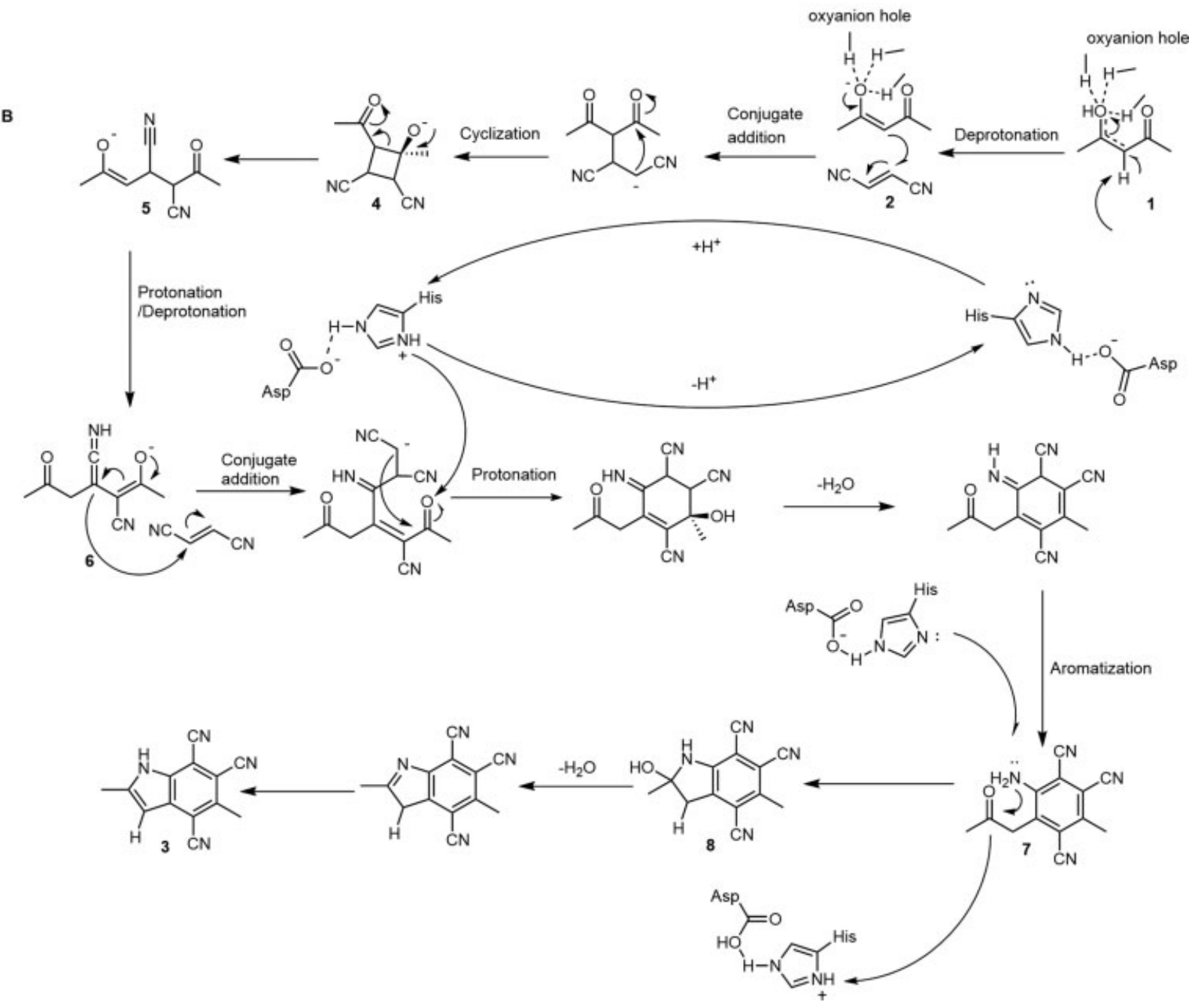

Scheme 2 (A) Lipase-catalyzed synthesis of cyano-containing multisubstituted indoles, and (B) a plausible reaction mechanism.

anion and the fumaronitrile 2 leads to the formation of carbanion, followed by attacking the carbonyl group to generate intermediate $\mathbf{4}$, which is converted into 1,5-diketone enolate $\mathbf{5}$; then $\mathbf{5}$ undergoes protonation/deprotonation process to produce intermediate $\mathbf{6}$; subsequently, $\mathbf{6}$ reacts with another molecule of fumaronitrile via the Michael addition, and then undergoes cyclization, protonation/ deprotonation, and aromatization to generate aniline intermediates $\mathbf{7}$. The amino group in the structure of $\mathbf{7}$ attacks the carbonyl group in the molecule under the activation of lipase to form a five-membered heterocyclic intermediate 8; finally, 8 undergoes dehydration and isomerization to produce the target product, polycyano-substituted indole $\mathbf{3}$.

Xiang et al first suggested lipase-catalyzed the reaction between aldehydes and indole to obtain bisindole. ${ }^{17}$ This process was conducted in a solvent mixture [1,4-dioxane containing $20 \%(\mathrm{v} / \mathrm{v})$ water] at $50^{\circ} \mathrm{C}$ using porcine pancreas Type II (PPL) as a catalyst. The yield was highly associated with the electronic nature of aldehyde substituents: aromatic aldehydes with electron-withdrawing substituents showed higher reactivity than those with electron-donating groups, and aliphatic aldehydes. Our research group has improved this reaction by using the immobilized lipase TLIM (derived from Thermomonas) to catalyze this reaction in pure water. Excitingly, this method has a broad substrate tolerance, including various aldehydes such as aromatic aldehydes, heterocyclic aldehydes, and aliphatic aldehydes substituted by various electron-withdrawing groups, electron-donating groups, and large steric hindrance groups. The amount of enzyme $(2 \mathrm{mg} / \mathrm{mL})$ is much lower than that of 


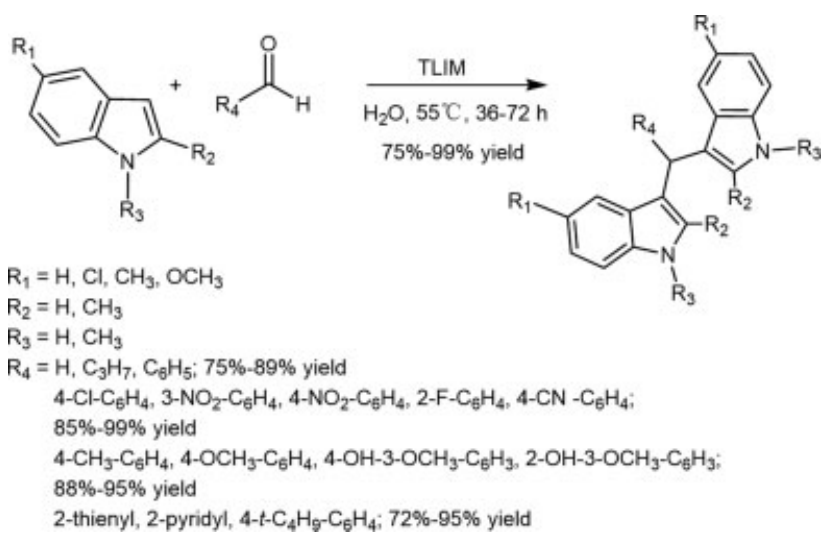

Scheme 3 Lipase-catalyzed synthesis of bis(indolyl)methanes.

ordinary enzymatic reactions, and after repeated use, the catalytic activity of enzymes is still good (-Scheme 3 ). ${ }^{18}$

\section{Synthesis of Five-Membered Heterocyclic Compounds Containing Oxygen}

Furan compounds have been widely used in the field of medicine. Currently, there are more than 10 furan drugs in clinical application. ${ }^{19}$ In 2021, Liu et al presented a novel synthesis method of polyhydroxyalkyl furans, which is based on the lipase-catalyzed Knoevenagel/oxo-Michael/ThorpeZiegler cascade reaction in pure water. ${ }^{20}$ This method used reducing sugars and malononitrile as substrates, selected various lipases, such as lipase B from Candida antarctica (CALB), Pseudomonas cepacia lipase (PSL), Novozym435 (immobilized CALB), PPL as well as CRL, as catalysts, and acquired moderated to good yield (55-88\%) (- Scheme 4A). It is worth to notify that Novozym435 showed the highest catalytic efficiency in comparison to other lipases. The authors proposed the catalytic mechanism as follows: first,

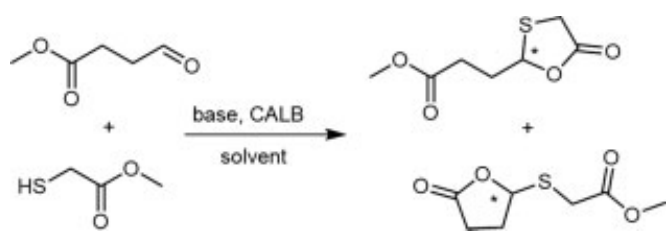

Scheme 5 Lipase-catalyzed synthesis of five-membered lactones.

the active methylene group in the malononitrile structure is deprotonated by the lipase-catalyzed triad and the oxygen anion hole; second, another substrate glucose and deprotonated malononitrile undergo the Knoevenagel condensation reaction to produce intermediate $\mathbf{1}$; then, intermediate 1 rapidly undergoes the lipase-catalyzed oxo-Michael/Thorpe-Ziegler reaction to obtain intermediate 2; finally, polyhydroxyalkyl furan is generated by spontaneous aromatization and ring opening reaction of intermediate 2 (-Scheme 4B).

The five-membered lactone ring is a special furan derivative structure. In 2019, Xu and Hu used cascade lipase CALBcatalyzed lactonization to achieve dynamic hemithioacetal formation, leading to efficient synthesis of five-membered lactone with chiral discrimination (-Scheme 5). ${ }^{21}$ Solventdependent regioselectivity was observed for the selective formation of 1,3-oxathiolan-5-one in weakly polar solvents, and $\gamma$-butyrolactone in the polar tetrahydrofuran (THF) solvent. Gutman et al realized that PPL could catalyze intramolecular transesterification of $\gamma$-hydroxy esters in the organic phase to obtain optically active $\gamma$-butyrolactones (-Scheme 6). ${ }^{22}$ Organic solvents with strong hydrophobicity are beneficial to the reaction. The initial reaction rate in $n$ hexane is two to four times those of solvents, such as ether, THF, and chloroform, yet, the reaction cannot proceed in an aqueous system. The study also suggested that the initial reaction rate of the $\gamma$-position of the substrate

A<smiles>O[C@@H]1[C@H](O)[C@H](O)OC[C@H]1O</smiles>

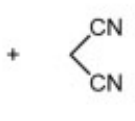

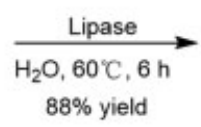<smiles>N#Cc1cc([C@@H](O)CO)oc1N</smiles>

B

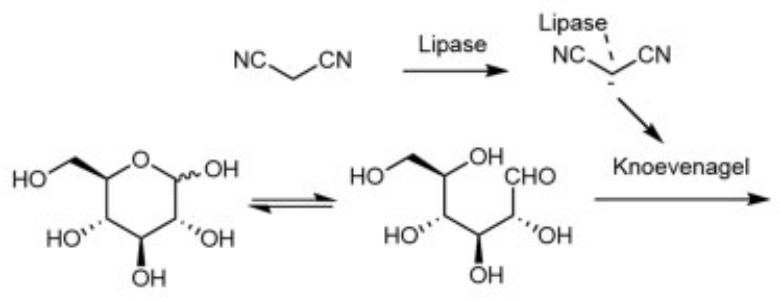

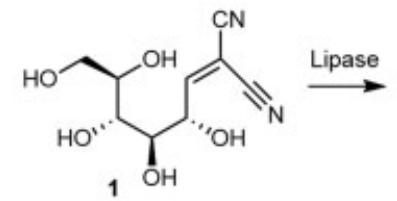

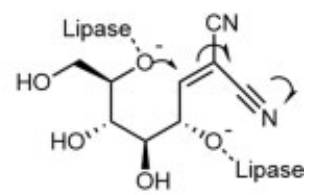<smiles>N#Cc1cc([C@@H](O)[C@@H](O)CO)oc1N</smiles>

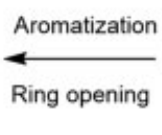<smiles>N#CC1=C(N)O[C@H]2C[C@H](O)[C@@H](O)[C@@H](CO)O[C@H]12</smiles><smiles>CCOC1CCCC1</smiles>

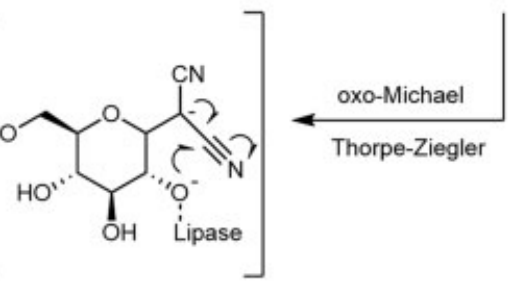

Scheme 4 (A) Lipase-catalyzed synthesis of polyhydroxyalkyl furans, and (B) a plausible reaction mechanism. ${ }^{20}$ 


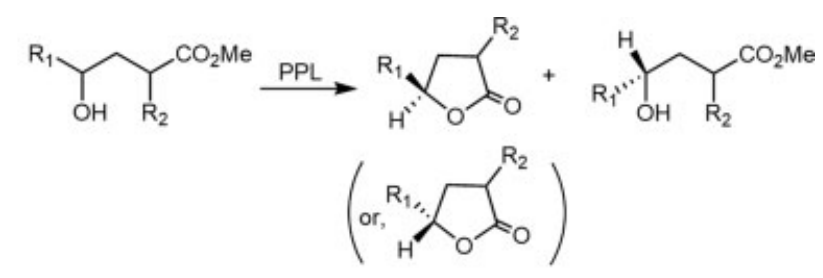

a: $R_{1}=H, R_{2}=H$

b: $\mathrm{R}_{1}=\mathrm{CH}_{3}, \mathrm{R}_{2}=\mathrm{H}$

c: $\mathrm{R}_{1}=\mathrm{C}_{2} \mathrm{H}_{5}, \mathrm{R}_{2}=\mathrm{H}$

d: $R_{1}=\mathrm{C}_{6} \mathrm{H}_{13}, \mathrm{R}_{2}=\mathrm{H}$

e: $\mathrm{R}_{1}=\mathrm{C}_{8} \mathrm{H}_{17}, \mathrm{R}_{2}=\mathrm{H}$

f: $\mathrm{R}_{1}=\mathrm{C}_{6} \mathrm{H}_{5}, \mathrm{R}_{2}=\mathrm{H}$

Scheme 6 Lipase-catalyzed synthesis of optically active $\gamma^{-}$ butyrolactones.

substituted by an alkyl group is about one order of magnitude faster than that substituted by an aryl group, and the configuration is just the opposite (the configuration of the alkyl-substituted lactone product is $S$, and the arylsubstituted the lactone product's configuration is $R$ ). Moreover, both the initial reaction rate and stereospecificity are significantly reduced when the substrate has a substituent at the $\alpha$-position.

\section{Synthesis of Six-Membered Heterocyclic Compounds}

Synthesis of Six-Membered Heterocyclic Compounds Containing Nitrogen

Pyridine and its derivatives have a wide range of applications. They can be used as denaturants, dye assistants, photosensitizers, color developers, etc. Some of them are important components of vitamins, enzymes, and coenzymes. ${ }^{23}$ Imidazo[1,2-a]pyridine is a valuable framework found in several nitrogen-containing heterocycles, and several drugs containing a pyridine core have been commercialized, such as zolpidem (a hypnotic drug), alpidem (anxiolytic drug), saripidem (anxiolytic drug), zolimidine (the antiulcer agent), as well as olprinone (a PDE-3 inhibitor for heart and circulatory failure therapy) (-Fig. 3). Budhiraja et al dis-

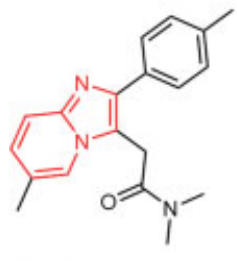

Zolpidem

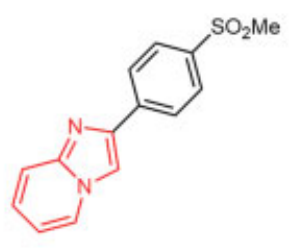

Zolimidine

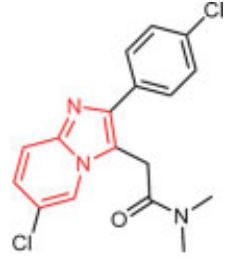

Alpidem
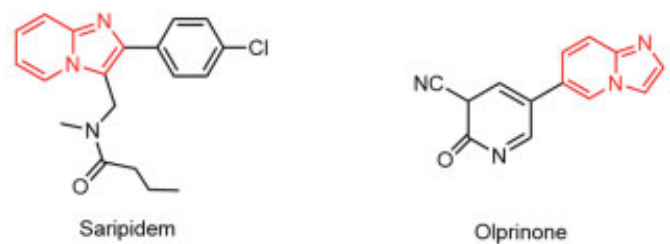

Fig. 3 Examples of drugs containing the imidazo[1,2-a]pyridine framework.

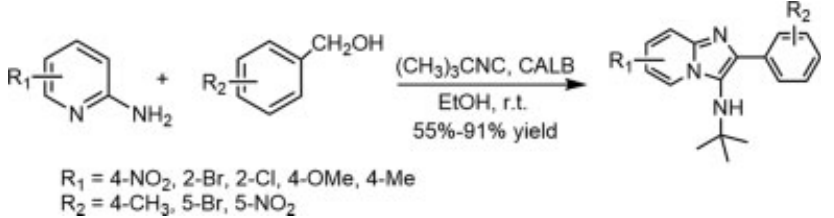

Scheme 7 Lipase-catalyzed synthesis of imidazo[1,2-a]pyridine derivatives.

closed the CALB-catalyzed Groebke-Blackburn-Bienaymé (GBB) multicomponent reaction, which was used for the synthesis of imidazo[1,2-a]pyridine derivatives from 2-aminopyridine, aromatic benzaldehyde, and isocyanides (-Scheme 7). ${ }^{24}$ They suggested that the reaction was greatly influenced by the different substituents on the aryl benzaldehyde and 2-aminopyridine ring. When there was a strong electron-withdrawing group $5-\mathrm{NO}_{2}$ in the 2-aminopyridine ring structure, the reaction could not proceed. Molecular docking and molecular dynamics simulations showed that Thr40 and Ser105 residues in the CALB peptide chain played a crucial role in catalyzing the multicomponent reaction of GBB.

Quinoline (benzopyridine) is a research hotspot in nitrogen-containing six-membered heterocyclic benzo systems, and is widely used in medicine, agriculture, printing, dyeing and other fields. ${ }^{25,26}$ In 2012, Zheng et al reported a lipasecatalyzed reaction between 2 -amino-3,5-dibromobenzaldehyde and cyclopentanone to synthesize quinoline derivatives (- Scheme 8A). ${ }^{27}$ The reaction could be catalyzed by PPL, pepsin, albumin from bovine, and other enzymes with the best catalytic effect being found in PPL $(15 \mathrm{mg} / \mathrm{mL})$. The yield can be achieved at $95 \%$. The authors proposed the reaction mechanism as the following: lipase promotes the formation of enolate intermediates, which undergo aldol reaction with

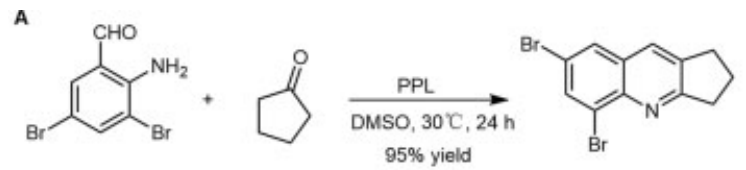

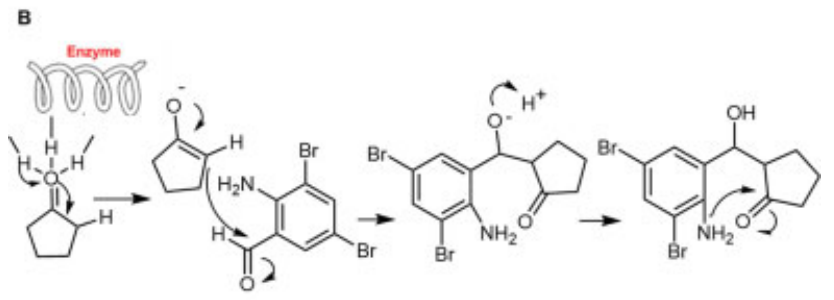

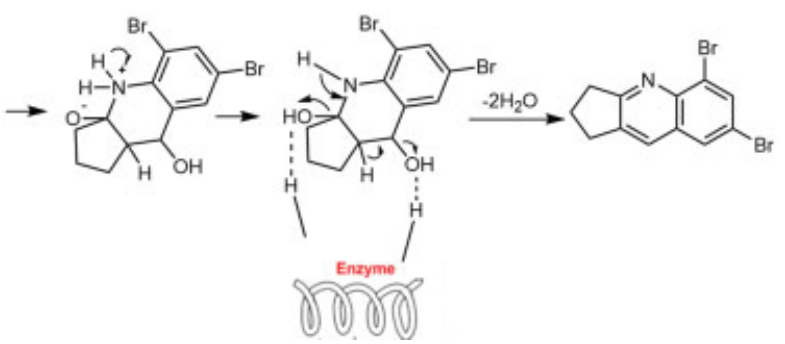

Scheme 8 (A) Lipase-catalyzed synthesis of quinoline derivatives, and (B) a plausible reaction mechanism. 

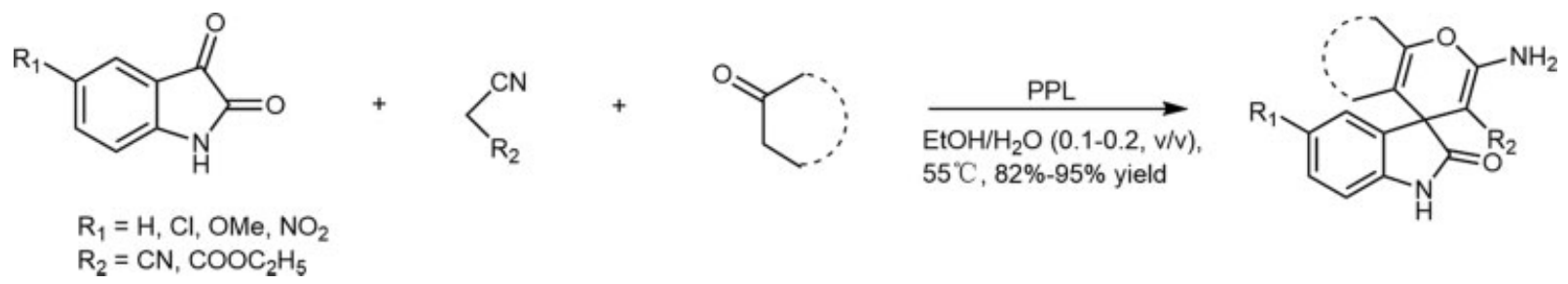

Scheme 9 Lipase-catalyzed synthesis of $4 H$-pyran derivatives with spiro structure.

the substrate 2-amino-3,5-dibromobenzaldehyde, and subsequently, intramolecular cyclization was performed through enzyme-assisted dehydration to generate the quinoline products (-Scheme $\mathbf{8 B}$ ).

\section{Synthesis of Six-Membered Heterocyclic Compounds Containing Oxygen}

Pyran compounds are common six-membered heterocyclic compounds containing one oxygen heteroatom. There are two isomers of pyran: $\alpha$-pyran ( $2 H$-pyran) and $\gamma$-pyran $(4 H-$ pyran) with neither of them being found naturally, but their derivatives are widely found in nature. Among the pyran derivatives, benzopyrans, namely chromones, have exhibited a broad range of physiological activities, such as antioxidant, anticancer, antibacterial, antiallergic and anti-human immunodeficiency virus (HIV) activities. ${ }^{28,29}$ Pyran compounds also exhibit inhibitory activity of cholinesterase, ${ }^{30}$ and therefore can be used to treat neurodegenerative diseases such as Parkinson's disease, Alzheimer's disease, Huntington's disease, etc. Chai et al reported that PPL can efficiently catalyze the Knoevenagel condensation-Michael addition cascade reaction of isatin, malononitrile/ethyl cyanoacetate, and various carbonyl compounds in $\mathrm{EtOH} / \mathrm{H}_{2} \mathrm{O}$ solvent to produce $4 H$-pyran compounds with a spiro ring

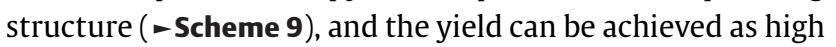
as 82 to $95 \% .^{31}$

In 2011, Xu et al first reported that PPL could efficiently catalyze the one-pot condensation of aldehyde, 1,3-cyclohexanedione, and malononitrile in a $10 \%(\mathrm{v} / \mathrm{v})$ ethanol to produce $4 \mathrm{H}$-pyridine in a yield of more than $90 \%{ }^{32}$ However, when the malononitrile was replaced by ethyl cyanoacetate, the yield would be significantly reduced. Based on the previous study, our research group further optimized the reaction by screening the catalytic activity of other lipases. We found that immobilized lipase TLIM could efficiently catalyze the condensation reaction of aromatic aldehyde/aliphatic aldehyde/heterocyclic aldehyde, 1,3cyclohexanedione, and malononitrile/ethyl cyanoacetate, with a good to excellent yield (82-99\%). When 1,3-cyclohexanedione was replaced by 4-hydroxycoumarin, the reaction also proceeded successfully (yield: 75-99\%) (-Scheme 10A). Our data also showed that lipase TLIM had a broad spectrum of substrates, and the yield was still good after five repeated uses of the enzyme. ${ }^{33}$ Compared with the traditional chemical methods, our reaction system offers great advantages in terms of temperature, catalyst reusability, and target product yield. ${ }^{34-36}$ The reaction mechanism is proposed as following: first, the Knoevenagel condensation reaction of 4-chlorobenzaldehyde $\mathbf{1}$ and malononitrile $\mathbf{2}$ takes place to obtain intermediate product $\mathbf{4}$; then, 4 combined with 4-hydroxycoumarin $\mathbf{3}$ via the Michael addition reaction to obtain intermediate $\mathbf{5}$, which undergoes enolization, cyclization, and isomerization to produce the target product 6 (4H-pyran) (-scheme 10).

In 2015, Yang et al suggested the PPL-catalyzed reaction of salicylaldehyde, 2,4-pentanedione, and aliphatic alcohol for the synthesis of $2 \mathrm{H}$-chromene derivatives in aqueous $\mathrm{DMF} / \mathrm{H}_{2} \mathrm{O}$ solvent (-Scheme 11). ${ }^{37}$ With the increase in carbon chain, the reaction rate and yield will be decreased, and when the carbon chain length is greater than that of pentanol, the reaction cannot proceed.

Xanthones are also important six-membered heterocyclic compounds containing an oxygen heteroatom, which are sensitive to nucleophiles and light energy, so they are widely used in many fields such as medicine, materials science, etc. ${ }^{38,39}$ In 2018, our research group discovered a novel method for the synthesis of xanthones: lipase TLIM-catalyzed Knoevenagel-Michael cascade reactions of 1,3-diketones with aromatic aldehydes/heterocyclic aldehydes/aliphatic aldehydes in $n$-hexane (-Scheme 12). ${ }^{40}$ The yield can be up to 80 to $97 \%$. Target products of this reaction were usually ring-opened xanthone compounds, yet, ring-closed xanthones were formed when pyridine-2-carboxaldehyde/2,6-dichlorobenzaldehyde reacted with 1,3-cyclohexanedione under a high temperature or strong acid. It is worth mentioning that the structure of the target product may be different from that obtained by ordinary chemical methods when benzaldehyde (containing hydroxyl in the ortho position) reacted with 1,3-cyclohexanedione using this method. After three repeated uses of the lipase, the yield was significantly reduced.

Dicoumarol derivatives have a wide range of pharmacological and physiological activities. They can be used as a vitamin $\mathrm{K}$ antagonist to prevent blood clotting. ${ }^{41}$ They also have antibacterial activity and can be used as antifever medicine, etc. ${ }^{42}$ In 2019, Fu et al for the first time reported immobilized lipase RMIM (from Rhizomucor miehei)-catalyzed Knoevenagel-Michael cascade reaction, which was used to generate dicoumarol derivatives (-Scheme 13). ${ }^{43}$ The method tolerates the reaction of 4-hydroxycoumarin with various aldehydes (aromatic aldehydes/heterocyclic aldehydes/aliphatic aldehydes) in a pure water with a yield of 81 to $98 \%$. Circular dichroism spectroscopy revealed that the secondary structure of RMIM was changed after five times of repeated use of the enzyme. When the ratio of $\alpha$ helix and $\beta$-fold was decreased, the enzyme activity was reduced, yet, the yield of the reaction was still $81 \%$. 


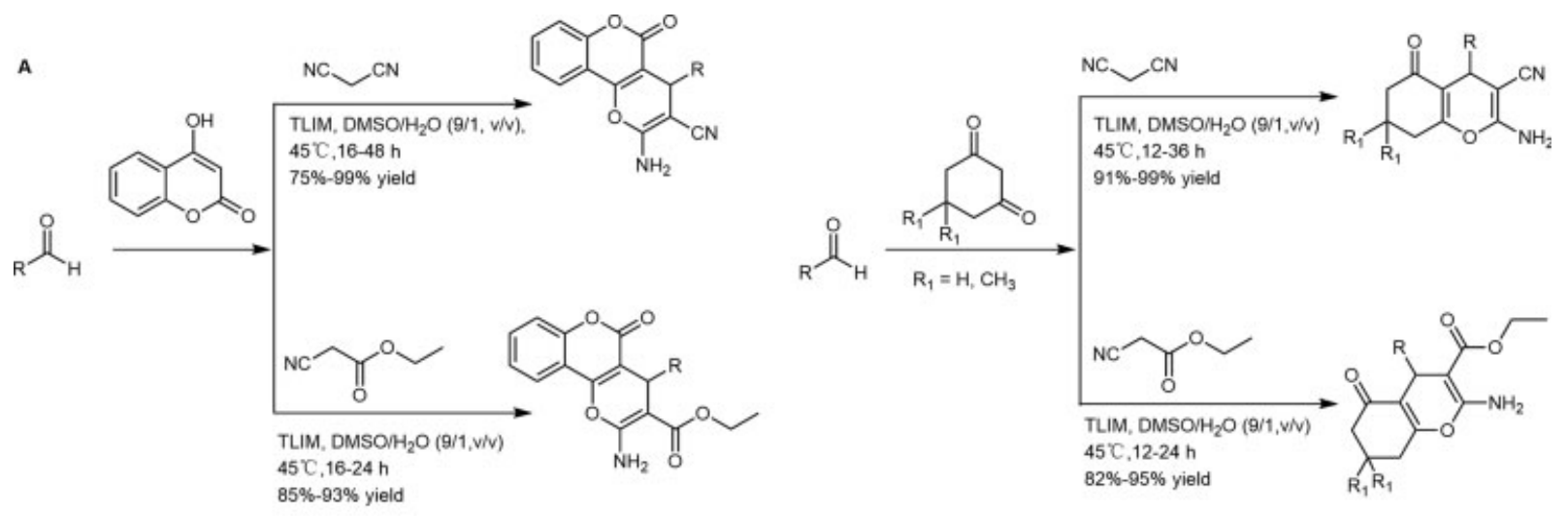

B

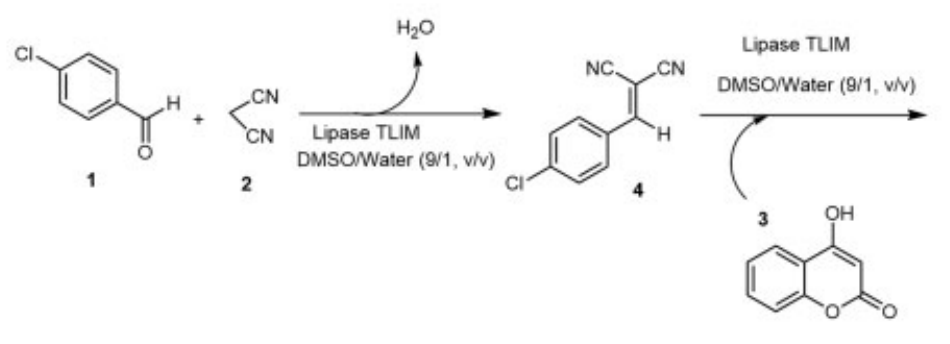<smiles>N#CC(C#N)=Cc1ccc(Cl)cc1</smiles><smiles>COC(=O)C(C(c1ccc(Cl)cc1)C(C#N)C#N)C(C)(C)C</smiles>

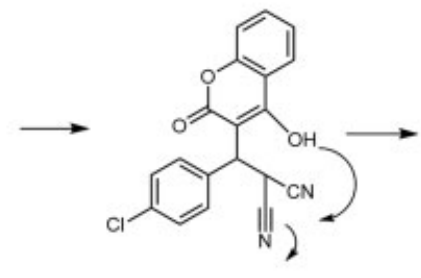

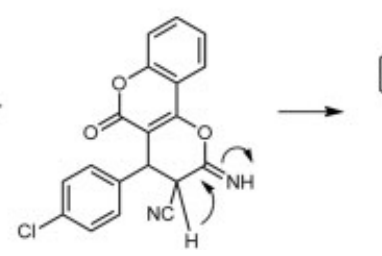<smiles>N#CC1=C(N)Oc2c(c(=O)oc3ccccc23)C1c1ccc(Cl)cc1</smiles>

6

Scheme 10 (A) Lipase-catalyzed synthesis of $4 \mathrm{H}$-pyran derivatives, and (B) a plausible reaction mechanism.

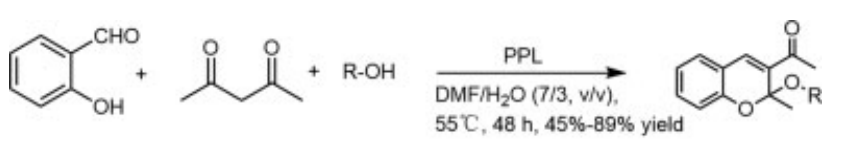

$\mathrm{R}=$ methyl, ethyl, butyl, pentyl, isopropyl, benzyle, phenethyl

Scheme 11 Lipase-catalyzed synthesis of $2 \mathrm{H}$-pyran derivatives.

\section{Synthesis of Other Heterocyclic Compounds}

Oxazolidinone derivatives are widely used in the treatment of acute bacterial skin infections and other severe infections induced by gram-positive bacteria and MRSA (methicillinresistant Staphylococcus aureus).$^{44}$ In 2015, the synthesis of chiral oxazolidinone through lipase-catalyzed kinetic resolution was first described. ${ }^{45}$ Lipase PS-IM (from Burkholderia cepacia) catalyzed the reaction of $\alpha$-amino alcohol and bisacyl donor carbonate in tert-butyl methyl ether at room temperature (r.t.), and the chiral oxazolidinone can be obtained with a certain ee\% value of up to $95 \%$ (-Scheme 14). However, to achieve the complete conversion of selected enantiomer, a longer reaction time was necessarily needed. Fortunately, a catalytic amount of the Lewis acid $\mathrm{SiO}_{2}$ can shorten the reaction time from 4 days to 3 hours with no erosion on the enantioselectivity of the product. The reaction mechanism is proposed as follows: the first step was kinetics-controlled carbamoylation, followed by lipase-catalyzed cyclization to obtain enantiomerically enriched oxazolidinone derivatives (- Scheme 14B).

Lipase can be used to catalyze intramolecular transesterification of hemithioacetals to synthesize 1,3-oxathiolan-5-

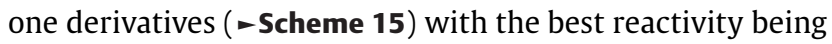
found in lipase CALB or novozyme $435 .{ }^{46}$ The reaction mechanism may be attributed to the following: first, under the catalysis of triethylamine, $\mathbf{1}$ (2-methylpropanal) and $\mathbf{2}$ (octanal) [or, $\mathbf{3}$ (pyridine-2-carbaldehyde)] react with mercaptan A (methyl 2-mercaptoacetate) or mercaptan B (methyl-3-mercaptopropionate) to produce $\gamma$ - and $\delta$-hydroxyl ester intermediates $\mathbf{1 A - 3 A}$ and $\mathbf{1 B}-\mathbf{3 B}$, respectively. Subsequently, lipase-catalyzed intramolecular transesterification to selectively generate $\gamma$-lactone. $\boldsymbol{\delta}$-Hydroxy ester intermediates (1B-3B) did not react during the enzymatic catalysis. The study also found that the rigidity of the enzyme structure will be increased at low temperatures, which can improve substrate selectivity and product enantioselectivity.

1,3-Oxazines are one class of the most important heterocyclic compounds, which possess a variety of pharmacological 
<smiles>[X]c1ccc(C2C3=C(CCCC3=O)OC3=C2C(=O)CCC3)cc1</smiles>

$\mathrm{R}=\mathrm{H}, \mathrm{CH}_{3}$

$\mathrm{X}=\mathrm{H}, 4-\mathrm{Cl}, 4-\mathrm{Br}, 4-\mathrm{F}, 3-\mathrm{Cl}, 2-\mathrm{F}, 2-\mathrm{NO}_{2}, 3-\mathrm{NO}_{2}, 4-\mathrm{NO}_{2}, 4-\mathrm{CN}, 4-\mathrm{CF}_{3}, 4-\mathrm{OCH}_{3}, 4-\mathrm{CH}_{3}, 4-\mathrm{OH}, 2-\mathrm{OH}$,

2-OH-3-OCH $, 4-\mathrm{OH}-3-\mathrm{OCH}_{3}, 4-\mathrm{C}_{4} \mathrm{H}_{9}$, 2-thienyl, 2,4-di-Cl

Scheme 12 Lipase-catalyzed synthesis of xanthone derivatives.

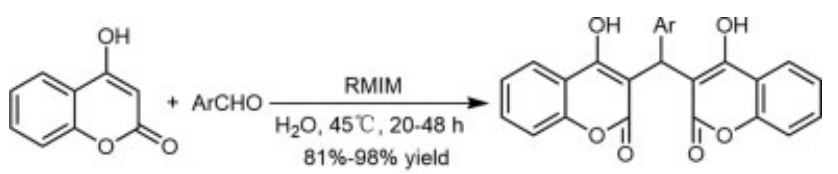

$\mathrm{Ar}=4-\mathrm{Cl}-\mathrm{C}_{6} \mathrm{H}_{4}, 2-\mathrm{NO}_{2}-\mathrm{C}_{6} \mathrm{H}_{4}, 2-\mathrm{NO}_{2}-\mathrm{C}_{6} \mathrm{H}_{4}, 4-\mathrm{NO}_{2}-\mathrm{C}_{6} \mathrm{H}_{4}, 4-\mathrm{F}-\mathrm{C}_{6} \mathrm{H}_{4}, 4-\mathrm{OH}-\mathrm{C}_{6} \mathrm{H}_{4}$, $\mathrm{C}_{6} \mathrm{H}_{5}, 4-\mathrm{Cl}_{6} \mathrm{C}_{6} \mathrm{H}_{4}, 4-\mathrm{CH}_{3}-\mathrm{C}_{6} \mathrm{H}_{4}, 4-\mathrm{OCH}_{3}-\mathrm{C}_{6} \mathrm{H}_{4}, 2-\mathrm{OH}-3-\mathrm{OCH}_{3}-\mathrm{C}_{8} \mathrm{H}_{3}, 2-\mathrm{OH}-\mathrm{C}_{6} \mathrm{H}_{4}$, 2,6- $\mathrm{Cl}_{2}-\mathrm{C}_{6} \mathrm{H}_{3}, 4-\mathrm{C}_{4} \mathrm{H}_{9}-\mathrm{C}_{6} \mathrm{H}_{4}, 2$-thienyl, 2-pyridyl, 3-indolyl

Scheme 13 Lipase-catalyzed synthesis of dicoumarol derivatives.

activities, such as bactericidal, antitumor, anti-HIV, anti-inflammatory, etc., and have been widely used in medicine. ${ }^{47}$ Zhang et al reported a combined catalytic system using lipase CALB and $\mathrm{Ru}(\mathrm{bpy})_{3} \mathrm{Cl}_{2}$ for the reaction of naphthol and ethyl $\mathrm{N}$ arylglycinate (instead of ethyl $\mathrm{N}$-alkylglycinate) to produce 1,3-oxazine derivatives (-Scheme 16). ${ }^{48}$ The reaction was conducted at r.t. in acetonitrile for 48 hours under a $12 \mathrm{~W}$ fluorescent bulb (Philips), and the yield achieved was 19 to $69 \%$. Ethyl $N$-arylglycinate with its electron-rich and electronneutral nature showed higher reactive activity in comparison to that with electron-withdrawing nature. Mechanistically, the protocol consists of sequential enzymatic hydrolysis and visible-light-excited decarboxylation of ethyl $\mathrm{N}$-aryl glycinate to generate $\alpha$-amino radicals, which are oxidized to give iminium ions. The Mannich reaction with $\beta$-naphthols, transimination, and intramolecular cyclization furnished the 1,3oxazine derivatives.

Heterospirocyclic compounds widely exist in various pharmacological agents and agricultural products, and can be used as anticancer, anticonvulsant, and antimicrobial agents. ${ }^{49}$ Wang et al reported the synthesis of spiroox- azine derivatives through immobilized CALB-initiated multicomponent reaction from nitrostyrene, cyclohexanone, $p$-nitrobenzaldehyde, and acetamide substrates, enabling six $\mathrm{C}-\mathrm{C} / \mathrm{C}-\mathrm{N}$ bonds and two heterocycles in one-pot operation (-Scheme 17A). ${ }^{50}$ When $p$-nitrobenzaldehyde was replaced by other aromatic aldehydes, the yield was very low. Substituted nitrostyrene with an oxygen group afforded better yields in comparison to other nitrostyrenes. Besides, during the reaction, acetamide could play a synergistic role with enzyme. Through isotope labeling and control experiments, a reasonable mechanism was proposed as the following: first, aldol reaction of $p$-nitrobenzaldehyde and cyclohexanone was catalyzed by CALB and acetamide to produce $\beta$-hydroxyketone (compound A) followed by condensation and hydrolysis in the presence of CALB to form enamine intermediate $\mathbf{C}$, then $\mathbf{C}$ underwent Michael addition with nitrostyrene and the intramolecular Nef reaction to produce intermediate $\mathbf{D}$, which was condensated with another molecule of cyclohexanone to form the target spiro product $\mathbf{E}$ ( $\mathbf{- S c h e m e ~ 1 7 B \text { ). }}$

\section{Conclusion and Perspectives}

With the development of lipase versatility, lipases catalyze a wide range of reactions, especially for the synthesis of many heterocyclic compounds that are difficult to be prepared by classical chemical methods. Lipase may represent a promising strategy for the green synthesis of drugs and intermediates. However, lipases from natural sources have shortcomings, such as intolerance to high temperature, extreme $\mathrm{pH}$, as well as poor stability in organic solvents, which limit its use in industry practice. 
A<smiles>[R][X]=CC=C(C=C[R])C(O)CN[R]</smiles><smiles>[R]OC(=O)O[R]</smiles><smiles>CCCC(C)C(C)(C)C</smiles>
$42 \%-50 \%$ yield<smiles>[R]N1C[C@H](c2ccccc2)OC1=O</smiles>

$$
\mathrm{R}=\mathrm{H}, \mathrm{Cl}
$$$$
\mathrm{R}_{1}=\mathrm{CH}_{3}, \mathrm{CH}_{2} \mathrm{CH}_{3},\left(\mathrm{CH}_{2}\right)_{3} \mathrm{CH}_{3} \text {, cyclopropyl, cyclopentyl, } \mathrm{C}\left(\mathrm{CH}_{3}\right)_{3}, \mathrm{C}_{6} \mathrm{H}_{5}
$$$$
\mathrm{R}_{2}=\mathrm{R}_{3}=\mathrm{C}_{6} \mathrm{H}_{5}
$$

B
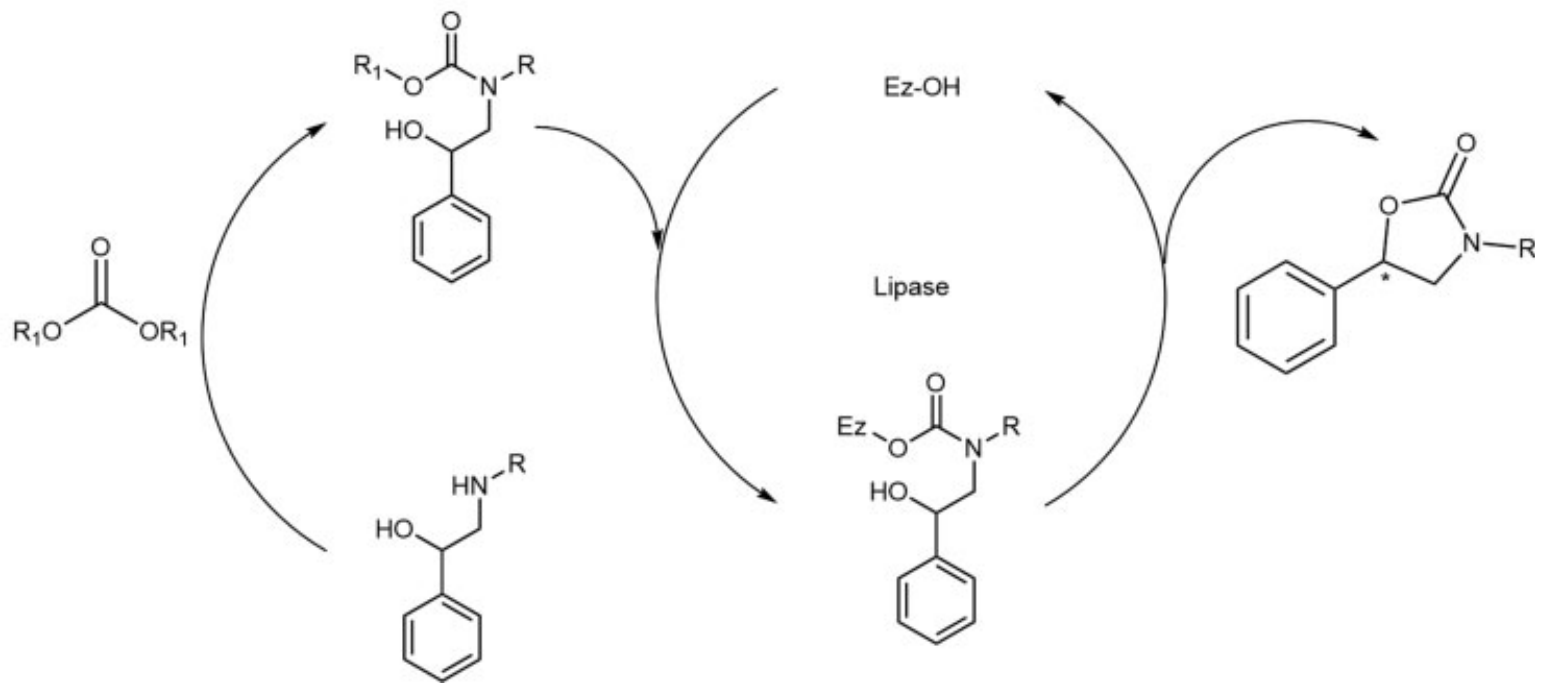

Scheme 14 (A) Lipase-catalyzed synthesis of chiral oxazolidinone derivatives, and (B) a plausible reaction mechanism.
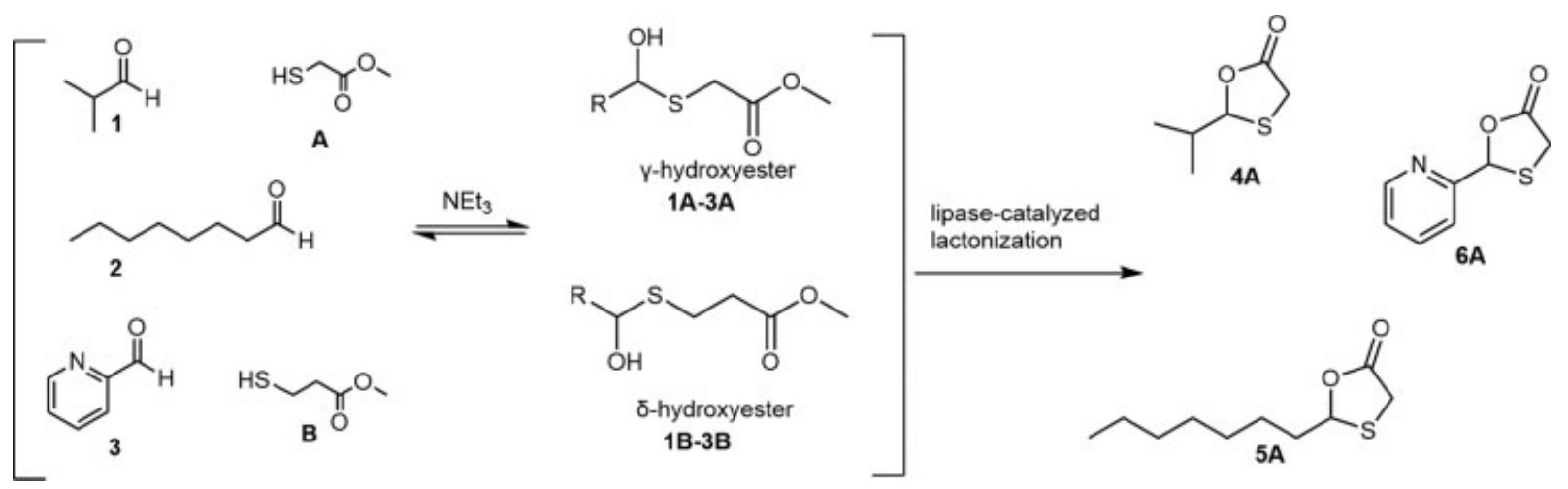

Scheme 15 Lipase-catalyzed synthesis of 1,3-oxathiolan-5-one derivatives.

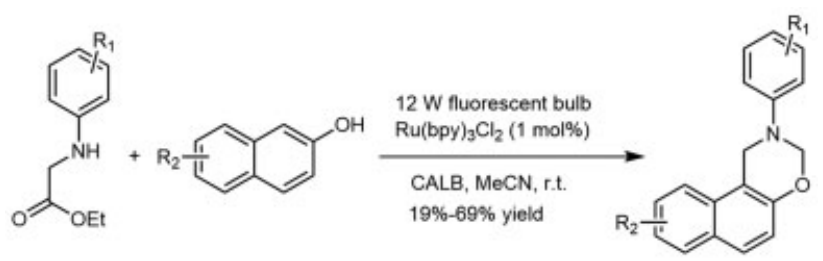

Scheme 16 Lipase-catalyzed synthesis of 1,3-oxazine derivatives.

X-ray crystallography makes the spatial structure of lipases readily available to scientists. With the development of molecular biology, lipase can be improved through molecular biological methods, such as directed evolution, sitedirected mutagenesis, chemical modification, immobilization, etc. to acquire stronger environmental tolerance, greater stability, as well as higher catalytic efficiency abilities. Furthermore, combined with the new technology of bioinformatics, the underlying mechanism of lipase-catalyzed reactions can be stated more clearly and in-depth. Last but not least, lipase-catalyzed strategies combined with traditional and novel organic synthesis methods may provide more options for the synthesis of target products, including chiral heterocyclic compounds. 
A<smiles>[R]C=C[N+](=O)[O-]</smiles>

B

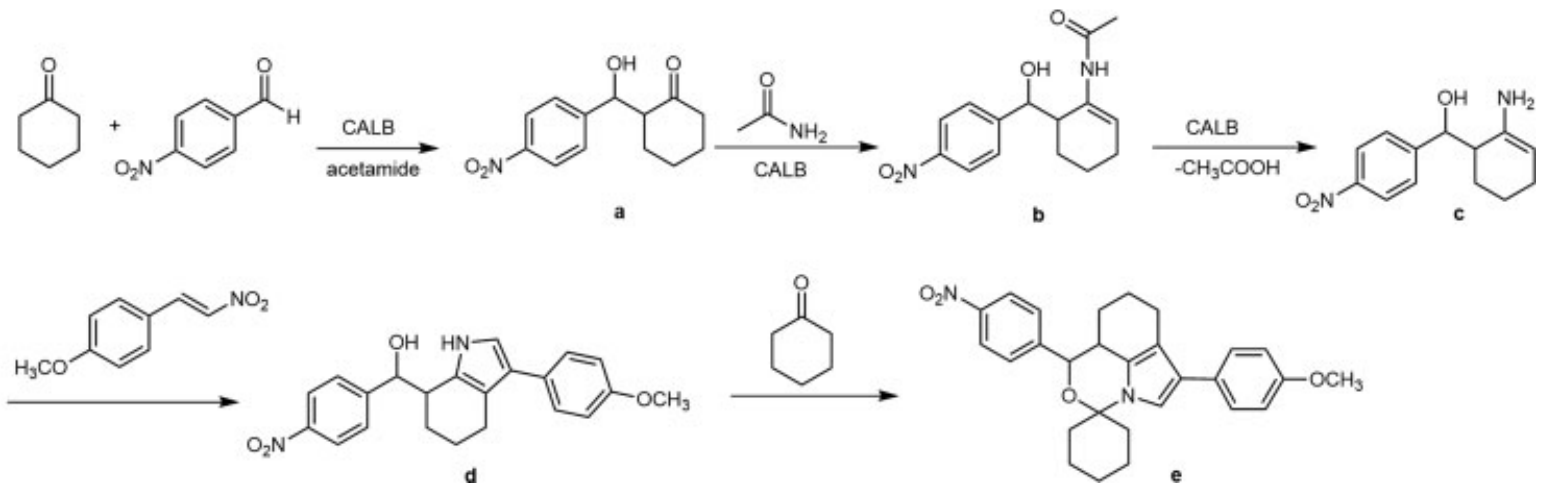

Scheme 17 (A) CALB and acetamide-catalyzed synthesis of spirooxazine derivatives, and (B) a plausible reaction mechanism.

Funding

This work was financially supported by the National Natural Science Foundation of China (Grant No. 21676143) and National Students' Platform for Innovation and Entrepreneurship Training Program (Grant No. 202010291006Z).

\section{Conflict of Interest}

The authors declare that they have no conflict of interest.

\section{References}

1 Mohammadi Ziarani G, Kheilkordi Z, Gholamzadeh P. Ultrasoundassisted synthesis of heterocyclic compounds. Mol Divers 2020; 24(03):771-820

2 Dhameliya TM, Donga HA, Vaghela PV, et al. A decennary update on applications of metal nanoparticles (MNPs) in the synthesis of nitrogen- and oxygen-containing heterocyclic scaffolds. RSC Advances 2020;10(54):32740-32820

3 Zhao Q, Meng G, Nolan SP, Szostak M. N-Heterocyclic carbene complexes in C-H activation reactions. Chem Rev 2020;120(04): 1981-2048

4 Mathur R, Negi KS, Shrivastava R, Nair R. Recent developments in the nanomaterial-catalyzed green synthesis of structurally diverse 1,4-dihydropyridines. Rsc Adv 2021;11(03):1376-1393

5 Sadjadi S. Magnetic (poly) ionic liquids: a promising platform for green chemistry. J Mol Liq 2021;323:114994

6 Barriuso J, Vaquero ME, Prieto A, Martínez MJ. Structural traits and catalytic versatility of the lipases from the Candida rugosalike family: a review. Biotechnol Adv 2016;34(05):874-885

7 Bilal M, Fernandes CD, Mehmood T, Nadeem F, Tabassam Q, Ferreira LFR. Immobilized lipases-based nano-biocatalytic systems - a versatile platform with incredible biotechnological potential. Int J Biol Macromol 2021;175:108-122

$8 \mathrm{Oz} \mathrm{M}$, Lorke DE, Kabbani N. A comprehensive guide to the pharmacologic regulation of angiotensin converting enzyme 2 (ACE2), the SARS-CoV-2 entry receptor. Pharmacol Ther 2021; 221:107750

9 Köhler-Forsberg O, Otte C, Gold SM, Østergaard SD. Statins in the treatment of depression: hype or hope? Pharmacol Ther 2020; 215:107625
10 Li X, Yang C, Wan H, et al. Discovery and development of pyrotinib: a novel irreversible EGFR/HER2 dual tyrosine kinase inhibitor with favorable safety profiles for the treatment of breast cancer. Eur J Pharm Sci 2017;110:51-61

11 Sorokin AB. Recent progress on exploring $\mu$-oxo bridged binuclear porphyrinoid complexes in catalysis and material science. Coord Chem Rev 2019;389:141-160

12 Zheng H, Shi Q, Du K, Mei Y, Zhang P. A novel enzyme-catalyzed synthesis of N-substituted pyrrole derivatives. Mol Divers 2013; 17(02):245-250

13 Qin HL, Liu J, Fang WY, Ravindar L, Rakesh KP. Indole-based derivatives as potential antibacterial activity against methicillin-resistance Staphylococcus aureus (MRSA). Eur J Med Chem 2020;194:112245

14 Iacopetta D, Catalano A, Ceramella J, et al. Synthesis, anticancer and antioxidant properties of new indole and pyranoindole derivatives. Bioorg Chem 2020;105:104440

15 Li F, Xu Y, Wang C, Wang C, Zhao R, Wang L. Efficient synthesis of cyano-containing multi-substituted indoles catalyzed by lipase. Bioorg Chem 2021;107:104583

16 Pike RAS, Sapkota RR, Shrestha B, et al. $\mathrm{K}_{2} \mathrm{CO}_{3}$-catalyzed synthesis of 2,5-dialkyl-4,6,7-tricyano-decorated indoles via carbon-carbon bond cleavage. Org Lett 2020;22(08):3268-3272

17 Xiang Z, Liu Z, Chen X, Wu Q, Lin X. Biocatalysts for cascade reaction: porcine pancreas lipase (PPL)-catalyzed synthesis of bis (indolyl)alkanes. Amino Acids 2013;45(04):937-945

18 Fu YJ, Lu ZP, Fang K, He XY, Xu HJ, Hu Y. Enzymatic approach to cascade synthesis of bis(indolyl)methanes in pure water. RSC Adv 2020;10(18):10848-10853

19 Don-Lawson C, Nweneka DO, Okah R, Orie KJ. Synthesis, characterization and bioactivity of 1,1-bis(2-carbamoylguanidino)furan-2-ylmethane. Am J Anal Chem 2020;11(06):261

20 Liu JX, Li FX, Zheng X, et al. Lipase-catalyzed synthesis of polyhydroxyalkyl furans from unprotected sugars and malononitrile. Process Biochem 2021;101:99-103

$21 \mathrm{Xu} \mathrm{J}, \mathrm{Hu}$ L. Asymmetric one-pot synthesis of five- and sixmembered lactones via dynamic covalent kinetic resolution: exploring the regio- and stereoselectivities of lipase. Tetrahedron Lett 2019;60(12):868-871

22 Gutman AL, Zuobi K, Bravdo T. Lipase-catalyzed preparation of optically active gamma-butyrolactones in organic solvents. J Org Chem 1990;55(11):3546-3552 
23 Shi YJ, Zhou Q, Wang Y, et al. Synthesis and biological activities of novel pyrazole amide derivatives containing substituted pyridyl group. Chin J Org Chem 2018;38(09):2450

24 Budhiraja M, Kondabala R, Ali A, Tyagi V. First biocatalytic Groebke-Blackburn-Bienaymé reaction to synthesize imidazo [1,2-a]pyridine derivatives using lipase enzyme. Tetrahedron 2020;76(47):131643

25 Stringer T, De Kock C, Guzgay H, et al. Mono- and multimeric ferrocene congeners of quinoline-based polyamines as potential antiparasitics. Dalton Trans 2016;45(34):13415-13426

26 Zablotskaya A, Segal I, Geronikaki A, Shestakova I, Nikolajeva V, Makarenkova G. N-Heterocyclic choline analogues based on 1,2,3,4-tetrahydro(iso)quinoline scaffold with anticancer and anti-infective dual action. Pharmacol Rep 2017;69(03):575-581

27 Zheng H, Liu J, Mei YJ, Shi QY, Zhang PF. A novel enzymatic synthesis of quinoline derivatives. Catal Lett 2012;142(05):573-577

28 Keri RS, Budagumpi S, Pai RK, Balakrishna RG. Chromones as a privileged scaffold in drug discovery: a review. Eur J Med Chem 2014;78:340-374

29 Semwal RB, Semwal DK, Combrinck S, Viljoen A. Health benefits of chromones: common ingredients of our daily diet. Phytochem Rev 2020;19(04):761-785

30 Sameem B, Saeedi M, Mahdavi M, et al. Synthesis, docking study and neuroprotective effects of some novel pyrano[3,2-c]chromene derivatives bearing morpholine/phenylpiperazine moiety. Bioorg Med Chem 2017;25(15):3980-3988

31 Chai SJ, Lai YF, Xu JC, Zheng H, Zhu Q, Zhang PF. One-pot synthesis of spirooxindole derivatives catalyzed by lipase in the presence of water. Adv Synth Catal 2011;353(2-3):371-375

32 Xu JC, Li WM, Zheng H, Lai YF, Zhang PF. One-pot synthesis of tetrahydrochromene derivatives catalyzed by lipase. Tetrahedron 2011;67(49):9582-9587

33 Fu Y, Lu Z, Ma X, et al. One-pot cascade synthesis of benzopyrans and dihydropyrano[c]chromenes catalyzed by lipase TLIM. Bioorg Chem 2020;99:103888

34 Gupta M, Gupta M, Rajnikant R, Gupta VK. Salicyldimine-based Schiff's complex of copper(II) as an efficient catalyst for the synthesis of nitrogen and oxygen heterocycles. New J Chem 2015;39(05):3578-3587

35 Bhosale RS, Magar CV, Solanke KS, Mane SB, Choudhary SS, Pawar RP. ChemInform abstract: molecular iodine: an efficient catalyst for the synthesis of tetrahydrobenzo[b]pyrans. ChemInform 2008;39(18):

36 Mohammadi AA, Asghariganjeh MR, Hadadzahmatkesh A. Synthesis of tetrahydrobenzo[b]pyran under catalysis of $\mathrm{NH}_{4} \mathrm{Al}$ $\left(\mathrm{SO}_{4}\right)_{2} \cdot 12 \mathrm{H}_{2} \mathrm{O}$ (Alum). Arab J Chem 2017;10:S2213-S2216
37 Yang FJ, Wang Z, Wang HR, Zhang H, Yue H, Wang L. ChemInform abstract: enzyme catalytic promiscuity: lipase catalyzed synthesis of substituted $2 \mathrm{H}$-chromenes by a three-component reaction. ChemInform 2015;46(05):25633-25636

38 Liu J, Zhang J, Wang H, et al. Synthesis of xanthone derivatives and studies on the inhibition against cancer cells growth and synergistic combinations of them. Eur J Med Chem 2017;133:50-61

39 Grzelakowska A, Kolinska J, Zaklos-Szyda M, Sokolowska J. Novel fluorescent fluorescent probes for L-cysteine based on the xanthone skeleton. J Photochem Photobiol Chem 2020;387:112153

40 Fu Y, Fan B, Chen H, Huang H, Hu Y. Promiscuous enzymecatalyzed cascade reaction: Synthesis of xanthone derivatives. Bioorg Chem 2018;80:555-559

41 Sun C, Zhao W, Wang X, Sun Y, Chen X. A pharmacological review of dicoumarol: an old natural anticoagulant agent. Pharmacol Res 2020;160:105193

$42 \mathrm{Li}$ J, Sui YP, Xin JJ, et al. Synthesis of biscoumarin and dihydropyran derivatives with promising antitumor and antibacterial activities. Bioorg Med Chem Lett 2015;25(23):5520-5523

43 Fu Y, Lu Z, Fang K, He X, Huang H, Hu Y. Promiscuous enzymecatalyzed cascade reaction in water: Synthesis of dicoumarol derivatives. Bioorg Med Chem Lett 2019;29(10):1236-1240

44 Kalam MA, Iqbal M, Alshememry A, Alkholief M, Alshamsan A. UPLC-MS/MS assay of Tedizolid in rabbit aqueous humor: application to ocular pharmacokinetic study. J Chromatogr B Analyt Technol Biomed Life Sci 2021;1171:122621

45 Zhang Y, Zhang Y, Ren Y, Ramström O. Synthesis of chiral oxazolidinone derivatives through lipase-catalyzed kinetic resolution. J Mol Catal, B Enzym 2015;122:29-34

46 Sakulsombat M, Zhang Y, Ramström O. Dynamic asymmetric hemithioacetal transformation by lipase-catalyzed $\gamma$-lactonization: in situ tandem formation of 1,3-oxathiolan-5-one derivatives. Chemistry 2012;18(20):6129-6132

47 Lathwal A, Mathew BP, Nath M. Syntheses, biological and material significance of dihydro[1,3] oxazine derivatives: an overview. Curr Org Chem 2021;25(01):133-174

48 Zhang GY, Xiang Y, Guan Z, He YH. Enzyme and photoredox sequential catalysis for the synthesis of 1,3-oxazine derivatives in one pot. Catal Sci Technol 2017;7(09):1937-1942

49 Yan ZY, Li JL, Ye GT, et al. Fused multicyclic polyketides with a twospiro-carbon skeleton from mangrove-derived endophytic fungusEpicoccum nigrumSCNU-F0002. RSC Advances 2020;10(48): 28560-28566

50 Wang JL, Chen XY, Wu Q, Lin XF. One-pot synthesis of spirooxazino derivatives via enzyme-initiated multicomponent reactions. Adv Synth Catal 2014;356(05):999-1005 